This item was submitted to Loughborough's Research Repository by the author.

Items in Figshare are protected by copyright, with all rights reserved, unless otherwise indicated.

\title{
A study of the effects of metallic pins on SAR using a Specific Anthropomorphic Mannequin (SAM) Head Phantom
}

PLEASE CITE THE PUBLISHED VERSION

LICENCE

CC BY-NC-ND 4.0

\section{REPOSITORY RECORD}

Panagamuwa, C.J., W.G. Whittow, R.M. Edwards, and J.C. Vardaxoglou. 2019. "A Study of the Effects of Metallic Pins on SAR Using a Specific Anthropomorphic Mannequin (SAM) Head Phantom”. figshare. https://hdl.handle.net/2134/3056. 
This item was submitted to Loughborough's Institutional Repository by the author and is made available under the following Creative Commons Licence conditions.

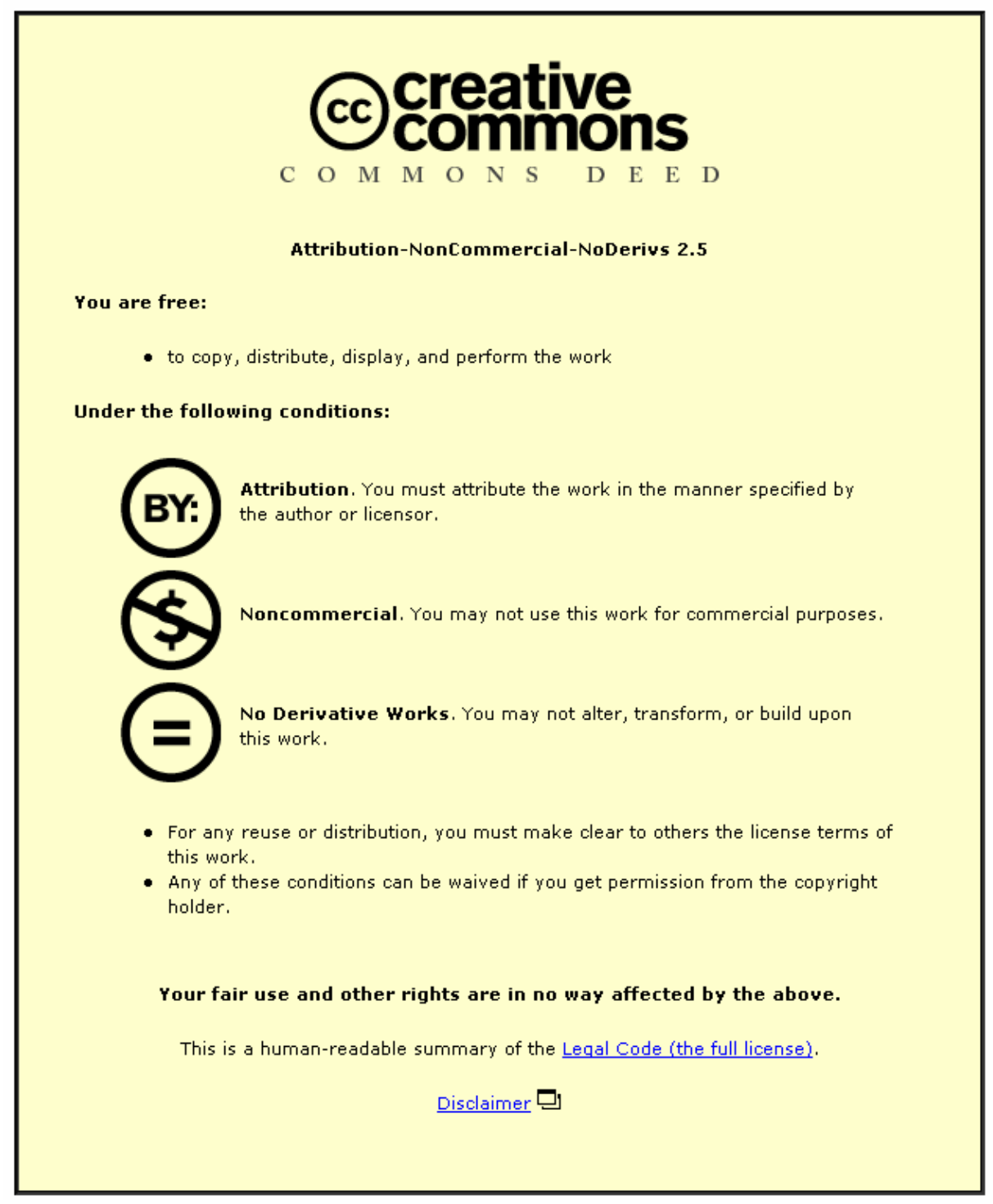

For the full text of this licence, please go to: http://creativecommons.org/licenses/by-nc-nd/2.5/ 


\title{
A STUDY OF THE EFFECTS OF METALLIC PINS ON SAR USING A SPECIFIC ANTHROPOMORPHIC MANNEQUIN (SAM) HEAD PHANTOM
}

\author{
C. J. Panagamuwa ${ }^{\dagger}$, W. G. Whittow ${ }^{\dagger}$, R. M. Edwards ${ }^{\dagger}$, J. C. Vardaxoglou ${ }^{\dagger}$ \\ ${ }^{\dagger}$ Electronic and Electrical Engineering Dept., Loughborough University, Leicestershire, LE11 3TU. UK, \\ c.j.panagamuwa@lboro.ac.uk,w.g.whittow@lboro.ac.uk,r.m.edwards@lboro.ac.uk, \\ j.c.vardaxoglou@lboro.ac.uk
}

Keywords: SAR, FDTD, DASY4, SAM Phantom, Metallic jewellery

\begin{abstract}
This paper presents the effects of facial metallic pins on the Specific Absorption Rate (SAR) in the head, when radiated by a microwave source placed in front of the face. A Specific Anthropomorphic Mannequin (SAM) is adapted for use with a DASY4 and a digitised SAM head is modelled using inhouse Finite-Difference Time-Domain (FDTD) code, enabling comparisons between measurements and simulations. A continuous wave $(\mathrm{CW})$ half-wave dipole is placed in front of the face, representing a communications enabled personal data assistant mobile communications equipment (PDAMCE). Parametric studies have shown that metallic pins that are roughly half a wavelength long placed along the eyebrow, increase the $1 \mathrm{~g}$ and $10 \mathrm{~g}$ SARs at $900 \mathrm{MHz}$ by around five fold. A greater than five fold increase is seen at $1800 \mathrm{MHz}$. Measurements show very good agreement with simulations.
\end{abstract}

\section{Introduction}

The interaction of energy from mobile phones into the head is a topical area of research. In order to allow meaningful comparisons to be made between different types of devices, a set of international standards have evolved that suggest maximum levels of radio frequency energy into humans and experimental techniques for modelling and measurement. A typical example is that of the IEEE head phantom that is commonly used to benchmark levels of energy delivered by mobile phones to the ear of a representative phantom [1].

Recently, Personal Data Assistants (PDAs) have begun to incorporate communications modules. With this new connectivity and their inherent large screens, mobile internet browsing is rapidly becoming a new trend among PDA users. This, along with the use of $3 \mathrm{G}$ video calls, has tended toward a device held in front of the face rather than to the ear. Studies in the past by the authors of this paper have shown that metallic spectacles of certain dimensions can increase the SAR in the eyes [2][3] when the face is illuminated by radio frequency energy from the front. Other FDTD studies have also examined the SAR in the eyes when radiated from in front of the face [4]-[6]. Measurements were carried out by Balzano [7] and Cleveland [8] using human skulls filled with brain simulating materials. While there are many FDTD based studies, measurements from in front of the face using the recently introduced IEEE SAM head phantom standard [1] are less common. The twin head phantom used in the standard DASY4 system [9] is designed specifically for sideof-head SAR measurements and so does not lend itself to front of face measurements [10]. The authors have recently modified a SAM head for SAR measurements behind the face, which can be used with a standard DASY4 kit. The suitability of the modified SAM head (which will be referred to as the Loughborough SAM head) for accurately measuring the SAR in the facial area has been verified through simulation [10] and experimentation [11].

With a standardised measurement system for in front of the face radiation sources now tested and verified, the effects of metallic jewellery on SAR can be reliably measured. In this paper, we present the effects on SAR of metallic pins placed in front of the face when radiated by $900 \mathrm{MHz}$ and $1800 \mathrm{MHz}$ dipole sources. The metal pins could represent the horizontal crossbars of half-rimed spectacles worn by many people today, an example of which is shown in Figure 1. The 3D graphic illustrates how a metal pin could be positioned to represent the crossbar of the shown glasses. Other sources of metal on the face could be from clip-on sunglasses worn over prescription glasses, rings, studs and piercings [12].
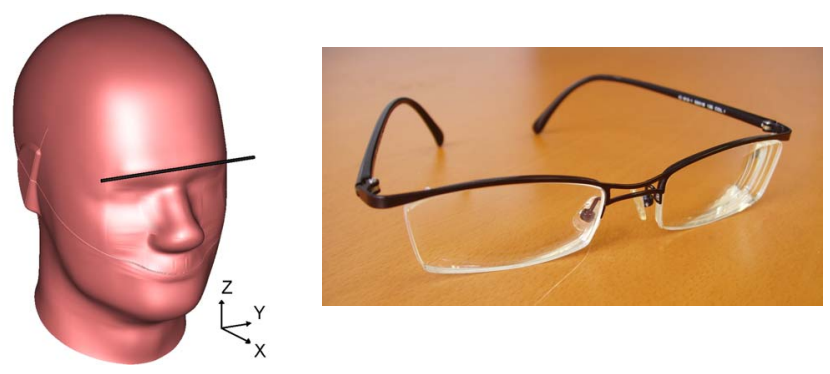

Figure 1 - Example of a half-rimmed spectacle and how it would be depicted in a simulation 


\section{Description of Model}

An in-house 3D FDTD code [2][3] has been written and verified against commercial software, and is used in this study. Perfectly Matched Layers (PML), with geometric grading [13], absorbing boundary conditions are used to terminate the grid. The PML is eight cells thick and is positioned at least twelve cells from the head. The Yee cell size used for simulations in Section 3 is $2 \mathrm{~mm}$. This allowed the parametric studies to be conducted quickly. At this resolution, the lowest number of cells per wavelength was always greater than ten at $1800 \mathrm{MHz}$, and reasonable results have been obtained with only four [5][14]. The time step was $3.336 \mathrm{pS}$. The simulations were run for at least ten cycles and until stability was achieved (at least 1660 time steps at $1800 \mathrm{MHz}$ ). The simulations in Section 4 use $1 \mathrm{~mm}$ Yee cells because following the contours of the face required a higher resolution. The geometry of the problem space is as follows; the $X$ axis runs from the tip of the nose to the back of the head, the $\mathrm{Y}$ axis is from ear to ear and the $\mathrm{Z}$ axis runs from chin to top of the head. The axis are shown in Figure 1 and 3.

SAR is the standard criteria to measure the amount of electromagnetic energy absorbed in the body and is calculated as in equation (1)

$$
S A R=\frac{\sigma|E|^{2}}{\rho} \quad(\mathrm{W} / \mathrm{kg})
$$

Where $|E|$ is the RMS magnitude of the electric field strength vector, $\rho$ is the mass density of the material in $\mathrm{kg} / \mathrm{m}^{3}$ and $\sigma$ is the electrical conductivity in $\mathrm{S} / \mathrm{m}$. The SAR is calculated in FDTD with the twelve-field approach as used by Caputa [15].

\subsection{Dipole model}

To allow accurate comparison between simulations and measurements, a dipole model [16] has been used as the excitation source in this study. The dipole is horizontally orientated along the $\mathrm{Y}$ axis (from ear to ear) and fed at its centre with a sinusoidal $\mathrm{CW}$ source. In the FDTD simulations, the $900 \mathrm{MHz}$ dipole is $162 \mathrm{~mm}$ long and the $1800 \mathrm{MHz}$ dipole is $74 \mathrm{~mm}$ long. The dipoles were modelled by setting the tangential E-field components to zero along the length of the dipoles. Both simulation and measurement results were normalised to $1 \mathrm{~W}$ transmitted power.

\subsection{The phantom head model}

The head model in this paper is based on the IEEE SAM head phantom [1]. The rear of the head has been removed to allow E-field probe of the DASY4 to access the inside of the face region. In the FDTD model, the original complete SAM head is descretised with a resolution of $2 \mathrm{~mm}$. Previous studies have shown that there is very little difference in SAR values between the complete SAM head and the truncated Loughborough SAM head. In the experimental setup, the phantom is fixed face down and filled with brain simulating liquid. The properties of the brain simulating liquid for both simulation and measurement at $900 \mathrm{MHz}$ are $\sigma=0.96 \mathrm{~S} / \mathrm{m}$, $\varepsilon \mathrm{r}=41.28, \rho=1000 \mathrm{~kg} / \mathrm{m}^{3}$ and at $1800 \mathrm{MHz}$ are $\sigma=1.37 \mathrm{~S} / \mathrm{m}$, $\varepsilon \mathrm{r}=40.48, \rho=1000 \mathrm{~kg} / \mathrm{m}^{3}$. The properties of the shell are $\sigma=0 \mathrm{~S} / \mathrm{m}, \varepsilon \mathrm{r}=3.5$, thickness $=2 \mathrm{~mm}$ in most areas except for at the joining seam and pinna. The Loughborough SAM head is shown incorporated into the DASY4 in Figure 2.

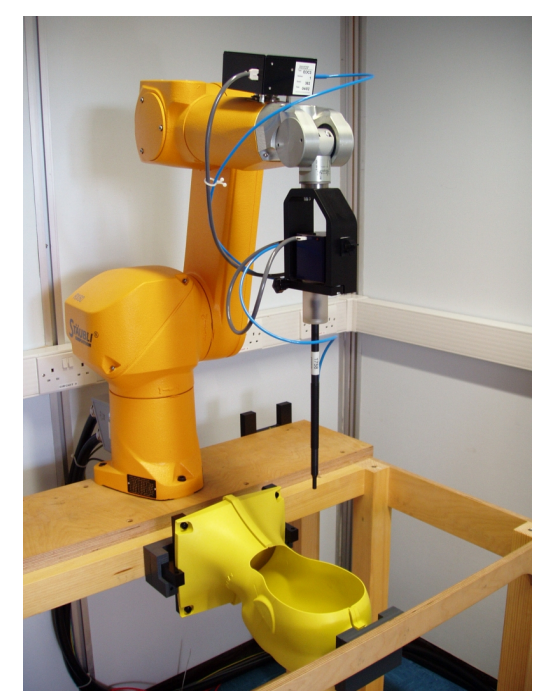

Figure 2 - Modified SAM head integrated into DASY4

At the join between the two halves of the head, there is a $17 \mathrm{~mm}$ wide seam. This has been reduced in the facial area to a seam that is $10 \mathrm{~mm}$ wide and $3 \mathrm{~mm}$ thick. We have previously shown that this reduced seam has negligible effects on the measured SAR [11].

\subsection{Modelling and geometry of metallic pins}

The location of the metallic pin and dipole relative to the SAM head phantom are shown in Figure 3.

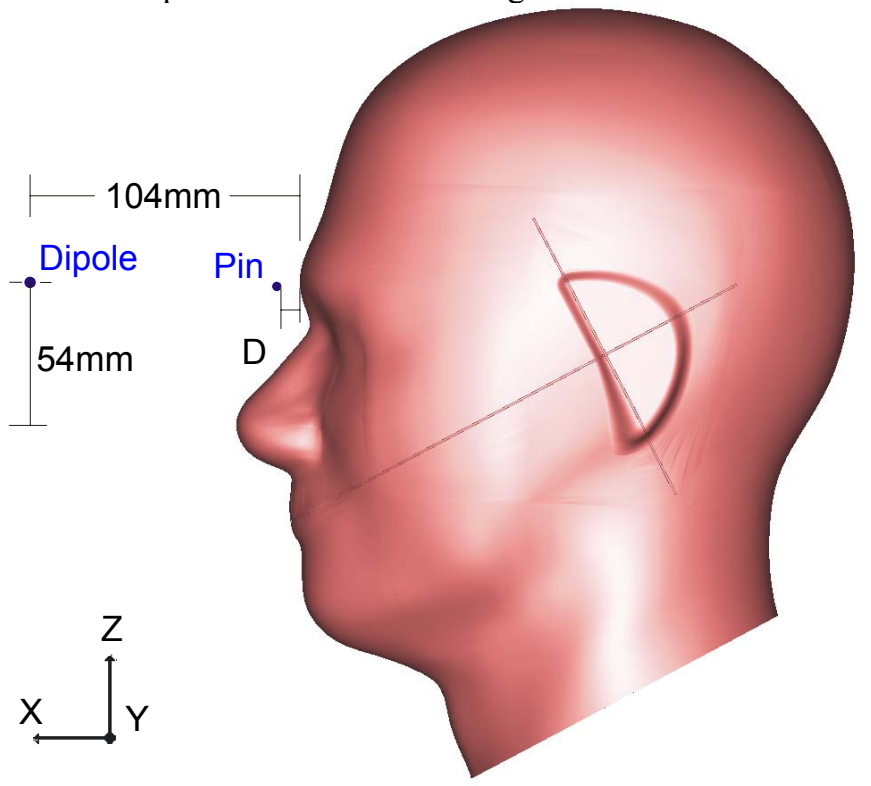

Figure 3 - Location of pin and dipole relative to the SAM head 
The pin was modelled in FDTD using metallic Yee cells, by setting the conductivity of the cells equal to the conductivity of copper [2]. This technique has been used by both Nikita [17] and Bernardi [18] in the past to model metallic shapes. The pins studied here are $2 \mathrm{~mm}$ thick ( 2 Yee cells). Both pin and dipole are aligned along the $\mathrm{Y}$ axis and are in the same $\mathrm{XY}$ plane. The eyebrow XY plane is defined as being $54 \mathrm{~mm}$ up from the tip of the nose in the $\mathrm{Z}$ direction. The dipole centre is located $104 \mathrm{~mm}$ from the phantom surface and is fixed for all simulations and measurements. The distance D, which is the separation between the pin and the phantom surface, is a variable and is the subject of further study in the proceeding section.

\section{Simulating Optimum Sizes and Locations for the Pins}

Using FDTD simulations initially, parametric studies were conducted to find the optimum pin length and location for causing maximum SAR in the head at both $900 \mathrm{MHz}$ and $1800 \mathrm{MHz}$. In Section 4, the optimum sizes and locations will then incorporated into the DASY4 to verify the simulated worst-case scenarios. Figure 4 shows the change in $1 \mathrm{~g}$ SAR as the pin length is increased at $1800 \mathrm{MHz}$. These results are at a fixed distance of $8 \mathrm{~mm}$ from the surface (measured from the outside surface of the pin to the outside surface of the SAM phantom). The dipole source is located as shown in Figure 3 and is $74 \mathrm{~mm}$ long. A sharp increase in the $1 \mathrm{~g} \mathrm{SAR}$ from $0.63 \mathrm{~W} / \mathrm{kg}$ to $4.95 \mathrm{~W} / \mathrm{kg}$ is noticed when a $70 \mathrm{~mm}$ long pin (corresponding to $0.42 \lambda$ ) is placed in front of the eyebrows. Pins shorter than $30 \mathrm{~mm}(0.18 \lambda)$ and pins longer than $85 \mathrm{~mm}(0.51 \lambda)$ only increase the $1 \mathrm{~g}$ SAR by a very small percentage.

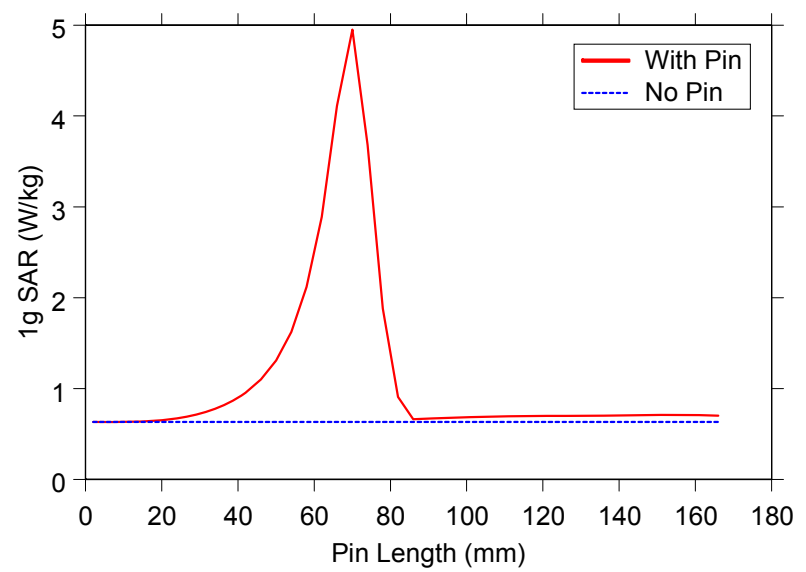

Figure 4 - 1g SAR at $1800 \mathrm{MHz}$ with increasing pin length (pin is $8 \mathrm{~mm}$ from the phantom surface)

Using the resonant length of $70 \mathrm{~mm}$, the location of the pin (distance D in Figure 3 ) is then varied in a similar FDTD parametric study. The change in $1 \mathrm{~g}$ SAR with increasing pin distance is shown in Figure 5. For this particular length ( $70 \mathrm{~mm})$, the optimum location for the pin is $8 \mathrm{~mm}$ from the surface of the SAM phantom

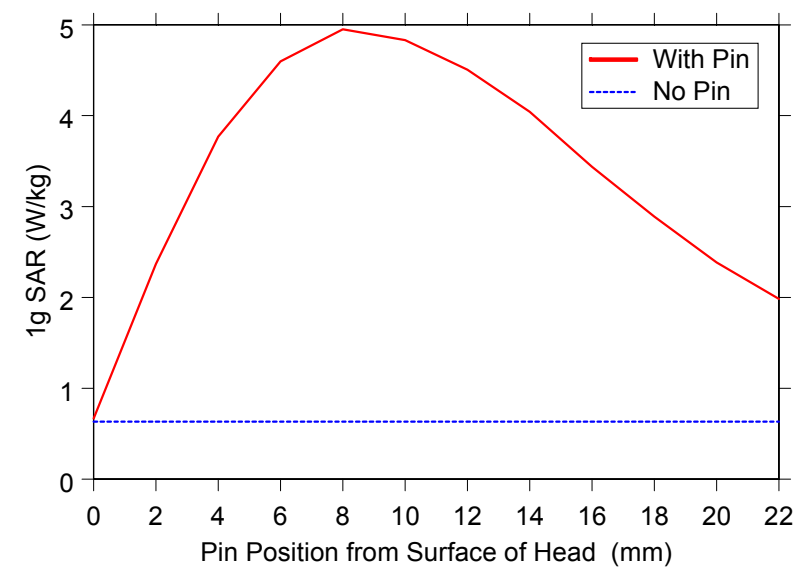

Figure 5 - $1 \mathrm{~g} \mathrm{SAR}$ at $1800 \mathrm{MHz}$ with increasing $70 \mathrm{~mm}$ pin distance from the phantom surface

A similar study for the $10 \mathrm{~g}$ SAR change with pin size and location showed that the optimum pin size was $70 \mathrm{~mm}$ and the optimum location was $10 \mathrm{~mm}$ from the SAM surface. The study was also repeated at $900 \mathrm{MHz}$. The dipole length was changed to $162 \mathrm{~mm}$ but the distance to the phantom remained unchanged. As the separation distance of $8 \mathrm{~mm}$ gives the biggest increase in $\mathrm{SAR}$ at $1800 \mathrm{MHz}$ and it is a realistic location for the crossbar of a semi-rimmed spectacle, the $900 \mathrm{MHz}$ pin length study also used the same distance. With the location of the pin fixed at $8 \mathrm{~mm}$ from the surface, the parametric study changed the length of the pin, observing the effect on the $1 \mathrm{~g}$ and $10 \mathrm{~g}$ SAR. The $1 \mathrm{~g}$ SAR values are shown in Figure 6. A sharp increase in the $1 \mathrm{~g}$ SAR from $0.40 \mathrm{~W} / \mathrm{kg}$ to $2.56 \mathrm{~W} / \mathrm{kg}$ is observed when the pin is $150 \mathrm{~mm}$ long, which corresponds to $0.45 \lambda$. Pins shorter than $\sim 0.27 \lambda$ have negligible effect on the SAR.

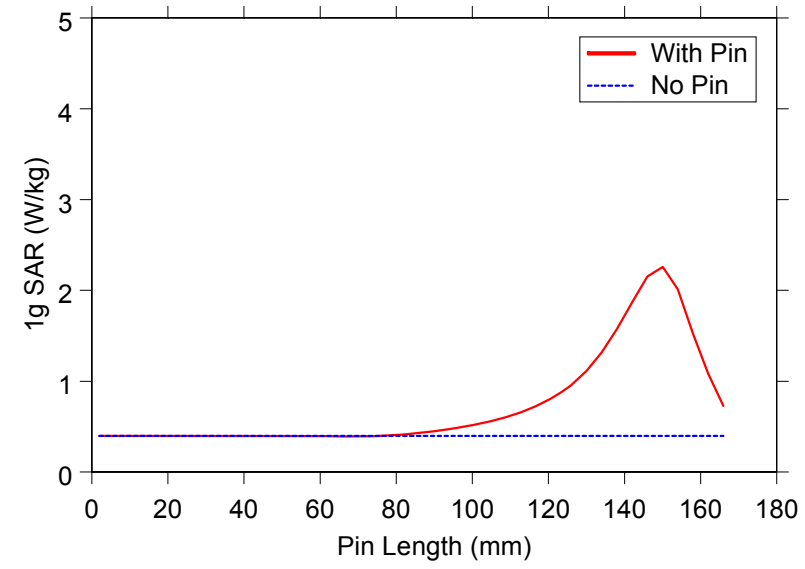

Figure $6-1 \mathrm{~g}$ SAR at $900 \mathrm{MHz}$ with increasing pin length (pin is $8 \mathrm{~mm}$ from the phantom surface)

With the pin length fixed at $150 \mathrm{~mm}$, the variation of $1 \mathrm{~g}$ SAR was studied at $900 \mathrm{MHz}$ with increasing pin/phantom separation distance D. The simulated results are presented in Figure 7. 


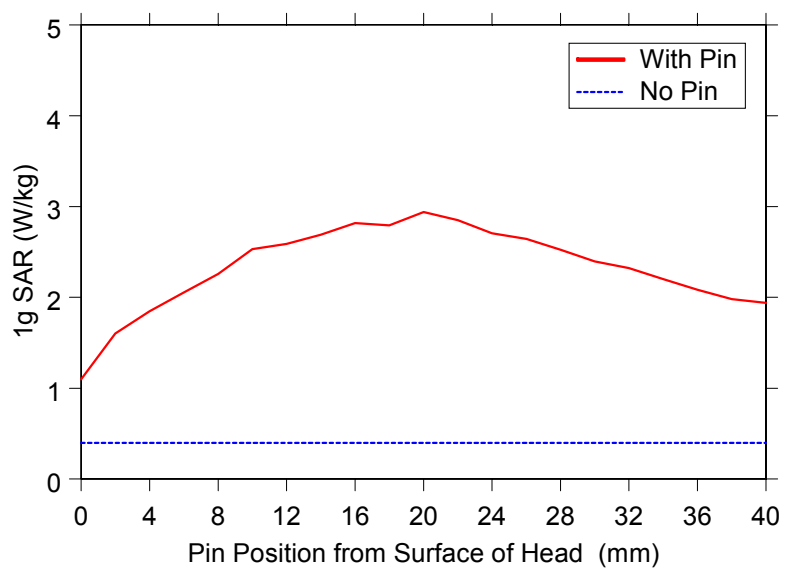

Figure 7 - 1g SAR at 900MHz with increasing $150 \mathrm{~mm}$ pin distance from the phantom surface

At $900 \mathrm{MHz}$, the optimum position for the $150 \mathrm{~mm}$ pin is $20 \mathrm{~mm}$ from the surface. The graph shows a more gradual increase in $1 \mathrm{~g}$ SAR with increasing separation distance compared to the $70 \mathrm{~mm}$ pin at $1800 \mathrm{MHz}$. Unlike previously, there is an obvious increase in the $1 \mathrm{~g}$ SAR when the pin is touching the phantom surface. This is most likely due to the size and shape of the Loughborough SAM head. The $150 \mathrm{~mm}$ pin length is comparable to the width of the phantom where as at $1800 \mathrm{MHz}$, the $70 \mathrm{~mm}$ pin was less than half the size. In the FDTD model, the central $42 \mathrm{~mm}$ of the eyebrow section is flat and so the $70 \mathrm{~mm}$ pin is touching the phantom surface for most of its length. Previous work by the authors [19] using a cubic phantom with varying pin sizes and locations showed that at $1800 \mathrm{MHz}$, all pin sizes touching the surface of the cubic phantom had negligible effect on the $1 \mathrm{~g}$ and $10 \mathrm{~g}$ SAR. However, in the $900 \mathrm{MHz}$ scenario, as the temples of the head curve away from the face towards the ears, the $150 \mathrm{~mm}$ pin only touches the phantom at a relatively small section of its full length. This is most likely to be the reason why the $1 \mathrm{~g}$ SAR in Figure 7 is increased at zero separation distance.

\section{Experimental Results}

In order to verify the simulated maximum SAR caused by the resonant pins, SAR measurements were carried out using the Loughborough SAM head incorporated into the DASY4. The optimum pin size for $1800 \mathrm{MHz}$ was $70 \mathrm{~mm}$ and at $900 \mathrm{MHz}$, the optimum pin length was $150 \mathrm{~mm}$. Although not impossible, the optimum separation distance of $20 \mathrm{~mm}$ for the pin at $900 \mathrm{MHz}$ was though to be less realistic regarding the spectacles scenario compared to the optimal separation distance of $8 \mathrm{~mm}$ for the pin at $1800 \mathrm{MHz}$. Therefore, SAR measurements at both frequencies were carried out with the pins located $8 \mathrm{~mm}$ from the phantom surface. Cotton thread was used to hang the pins in the correct locations. A small piece of Styrofoam was wedged between the pin and the phantom to ensure that the robot's movements did not destabilize the pin. It was assumed that the cotton and
Styrofoam have very little effect on the measured SAR. The DASY4 setup at $1800 \mathrm{MHz}$ is shown in Figure 8.

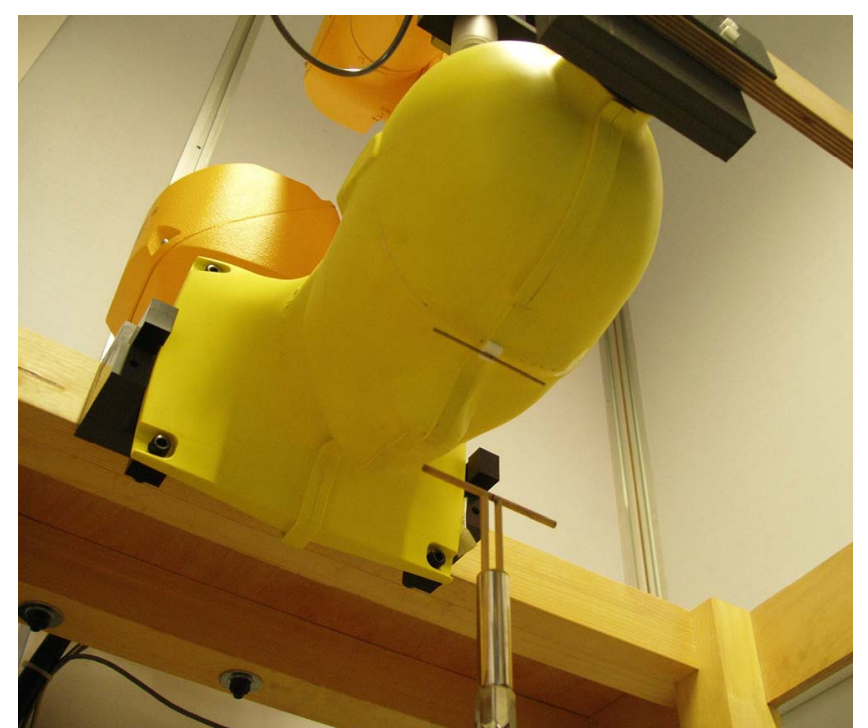

Figure 8 - Measurement setup at $1800 \mathrm{MHz}$

Local SAR measurements were taken along the inside of the Loughborough SAM head from ear to ear in the same XY plane as the dipole and pin. During the surface scans, the detectors inside the E-field probe were located $4 \mathrm{~mm}$ from the inside surface of the phantom. Therefore, in the simulations, the SAR values were also calculated $4 \mathrm{~mm}$ into the brain simulating liquid. Simulated and measured local SAR scans with and without the pins at $1800 \mathrm{MHz}$ and $900 \mathrm{MHz}$ are shown in Figure 9 and Figure 10 respectively.

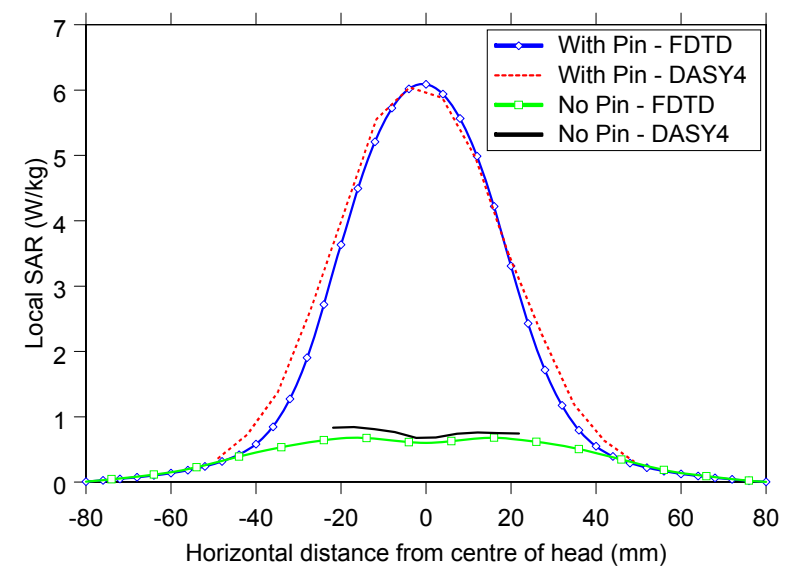

Figure 9 - Local SAR at $1800 \mathrm{MHz}$ along the inside surface of the phantom behind the pin

With the inclusion of pins, there is a very obvious increase in the local SAR inside the head directly behind the centre of the pins at both frequencies; more so at $1800 \mathrm{MHz}$. These measured and simulated local SAR values are actually $4 \mathrm{~mm}$ inside the surface, and so the inner surface local SAR values are naturally even higher. 


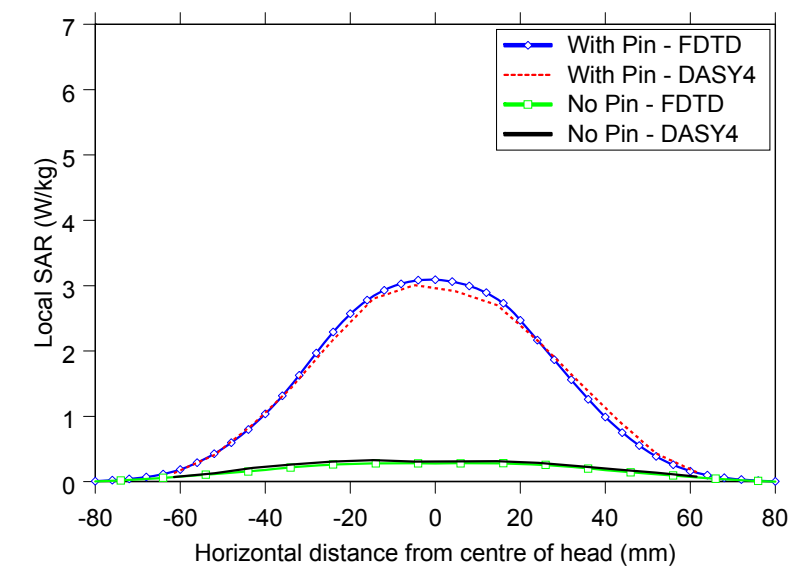

Figure 10 - Local SAR at $900 \mathrm{MHz}$ along the inside surface of the phantom behind the pin

There is very good agreement between measured and simulated results. The dip in the local SAR at the centre of the head without a pin is due to the shape of the eyebrows and eyes. As the eyes sockets curve into the head, the eyebrows protrude forward away from the face. As a result, the eyebrow region is exposed to radiation from a number of different angles. At the centre of the head, it is the nose bridge that curves into the head but this curvature is much less than that of the eye sockets. Therefore, the centre of the head is exposed to slightly less radiation. This results in a lower SAR at the central part of the head compared to the eyebrows either side.

In addition to surface scans, the DASY4 also calculated $1 \mathrm{~g}$ and $10 \mathrm{~g}$ SAR with and without pins at both $900 \mathrm{MHz}$ and $1800 \mathrm{MHz}$. Simulated and measured results are given in Table 1. The without pin results are in excellent agreement whereas the with pin results show some variations. This could be attributed to inaccuracies in placing the pin during measurements and the $2 \mathrm{~mm}$ staircasing effect in the FDTD code. At both frequencies, the $1 \mathrm{~g}$ and $10 \mathrm{~g}$ SARs increase by more than 5 times when the pins are introduced to the system.

\begin{tabular}{|c|c|c|c|c|c|c|}
\hline \multicolumn{8}{|c|}{ SAR at 900MHz (W/kg) $150 m m$ pin $8 \mathbf{m m}$ from surface } \\
\hline & \multicolumn{2}{|c|}{ No pin } & \multicolumn{2}{c|}{ With pin } & \multicolumn{2}{c|}{$\%$ increase } \\
\hline & Sim. & Meas. & Sim. & Meas. & Sim. & Meas. \\
\hline $1 \mathrm{~g}$ & 0.39 & 0.36 & 2.26 & 2.76 & 579 & 767 \\
\hline $10 \mathrm{~g}$ & 0.26 & 0.25 & 1.30 & 1.57 & 500 & 628 \\
\hline \multicolumn{7}{|c|}{} \\
\hline SAR at 1800MHz (W/kg) 70mm pin 8mm from surface \\
\hline \multicolumn{6}{|c|}{ No pin } & \multicolumn{2}{c|}{ With pin } & \% increase \\
\hline $1 \mathrm{~g}$ & 0.86 & 0.86 & 4.95 & 5.27 & 785 & 613 \\
\hline $10 \mathrm{~g}$ & 0.47 & 0.47 & 2.42 & 2.52 & 550 & 536 \\
\hline
\end{tabular}

Table 1 - Simulated and measured $1 \mathrm{~g}$ and $10 \mathrm{~g}$ SAR values inside the head with and without pin

\section{Conclusions}

This paper has investigated the effects of placing metallic pins in front of the eyebrows on SAR inside the head, when the head is subject to frontal microwave radiation. Detailed parametric studies in FDTD at $900 \mathrm{MHz}$ show that pins between $0.40 \lambda$ and $0.48 \lambda$ long increase the SAR inside the head, with peak increase occurring for a $0.45 \lambda(150 \mathrm{~mm})$ pin. At $1800 \mathrm{MHz}$, pins that are between $0.36 \lambda$ and $0.45 \lambda$ long resonate the most, with the largest effect now occurring when the pin is $0.42 \lambda(70 \mathrm{~mm})$ long. Longer and shorter pins only increase the SAR by very small amounts. There also appears to be optimum locations for the pins. At $900 \mathrm{MHz}$, the maximum $1 \mathrm{~g}$ SAR is produced when the pin is located $20 \mathrm{~mm}$ $(6 / 100 \lambda)$ from the surface of the phantom and at $1800 \mathrm{MHz}$, the optimum distance is $8 \mathrm{~mm}(\sim 5 / 100 \lambda)$. At both frequencies, the introduction of the pins increase the $1 \mathrm{~g}$ and $10 \mathrm{~g}$ SAR values by more than 5 fold. These results have been successfully verified through measurements using the Loughborough SAM head phantom and a DASY4.

Future work in this area will involve replicating this study using actual metallic semi-rimed spectacles and other everyday jewellery. The special case of pin touching the surface of the phantom at different frequencies also requires further study.

\section{References}

[1] IEEE Recommended Practice for Determining the Peak Spatial-Average Specific Absorption Rate (SAR) in the Human Head from Wireless Communications Devices: Measurement Techniques, IEEE Standard 1528-2003, 2003.

[2] W. G. Whittow and R. M. Edwards, "A study of changes to specific absorption rates in the human eye close to perfectly conducting spectacles within the radio frequency range 1.5 to $3.0 \mathrm{GHz}$ ", IEEE Trans. Antennas and Propagation, vol. 52, pp. 3207-3212, 2004.

[3] W. G. Whittow and R. M. Edwards, "Applications of a genetic algorithm for identification of maxima in specific absorption rates in the human eye close to perfectly conducting spectacles", IEE Proceedings Science, Measurement \& Technology, vol. 152, pp. 89-96, 2005.

[4] A. Taflove and M. E. Brodwin, "Computation of the electromagnetic fields and induced temperatures within a model of the microwave-irradiated human eye", IEEE Trans. Microwave Theory Technology, 1975. 23(11): p. 888-896.

[5] P. J. Dimbylow and O.P. Gandhi, "Finite-difference time-domain calculations of SAR in a realistic heterogeneous model of the head for plane-wave exposure from $600 \mathrm{MHz}$ to $3 \mathrm{GHz} "$, Physics in Medicine and Biology, 1991. 36(8): p. 1075-1089.

[6] A. Hirata, S. Matsuyama, and T. Shiozawa, "Temperature rises in the human eye exposed to EM waves in the frequency range $0.6-6 \mathrm{GHz}$," IEEE 
Transactions on Electromagnetic Compatibility, vol. 42, pp. 386-393, 2000.

[7] Q. O. Balzano, Garay and F. R. Steel, "Energy deposition in simulated human operators of 800$\mathrm{MHz}$ portable transmitters", IEEE Transactions on Vehicular Technology, 1978. 27(4): p. 174-182.

[8] R. F. Cleveland and T. W. Athey, "Specific absorption rate (SAR) in models of the human head exposed to hand-held UHF portable radios", Bioelectromagnetics, 1989. 10: p. 173-186.

[9] Schmid \& Partner Engineering AG, DASY4 Manual v4.1, March 2003

[10] C. J. Panagamuwa, W. Whittow, R. Edwards, J. C. Vardaxoglou and P. McEvoy, "A study of the validation of RF energy Specific Absorption Rates for simulations of anatomically correct head FDTD simulations and truncated DASY4 standard equipment measurements", European Conference on Antennas and Propagation, Nice, France, November 2006.

[11] C. J. Panagamuwa, W. G. Whittow, R. M. Edwards, and J. C. Vardaxoglou, "Experimental verification of a modified specific anthropomorphic mannequin (SAM) head used for SAR measurements," in 2007 Loughborough Antennas and Propagation Conference, Loughborough, UK, 2007, pp. 261-264.

[12] W. G. Whittow, C. J. Panagamuwa, R. M. Edwards, J. C. Vardaxoglou, "The SAR Effects of Popular Jewellery on the Human Head", The Second European Conference on Antennas and Propagation (EuCAP 2007), Edinburgh, UK, 2007

[13] J. P. Berenger, "A perfectly matched layer for the absorption of electromagnetic waves", Journal of Computational Physics, vol. 114, pp. 185-200, 1994.

[14] A. D. Tinniswood, C. M. Furse, and O. P. Gandhi, "Computations of SAR distributions for two anatomically based models of the human head using CAD files of commercial telephones and the parallelized FDTD code", IEEE Transactions on Antennas and Propagation, vol. 46, pp. 829-833, 1998.

[15] K. Caputa, M. Okoniewski, and M. A. Stuchly, "An algorithm for computations of the power deposition in human tissue", IEEE Antennas and Propagation Magazine, vol. 41, pp. 102-107, 1999.

[16] A. Taflove, Computational electrodynamics. The finite-difference time-domain method: Artech House, Inc., 1995.

[17] K. S. Nikita, M. Cavagnaro, P. Bernardi, N. K. Uzunoglu, S. Pisa, E. Piuzzi, J. N. Sahalos, G. I. Krikelas, J. A. Vaul, P. S. Excell, G. Cerri, S. Chiarandini, R. De Leo, and P. Russo, "A study of uncertainties in modeling antenna performance and power absorption in the head of a cellular phone user", IEEE Transactions on Microwave Theory and Techniques, vol. 48, pp. 2676-2685, 2000.

[18] P. Bernardi, M. Cavagnaro, and S. Pisa, "Evaluation of the SAR distribution in the human head for cellular phones used in a partially closed environment", IEEE Transactions on Electromagnetic Compatibility, vol. 38, pp. 357-366, 1996.

[19] W. Whittow, C. J. Panagamuwa, R. Edwards, J. C. Vardaxoglou, and P. McEvoy, "A study of head worn jewelry, mobile phone RF energy and the effect of differing tissue types on rates of absorption", in The First European Conference on Antennas and Propagation (EuCAP 2006), Nice, France, 2006. 